\title{
Preface to the New Edition
}

This edition seeks to introduce a new generation to Solomon Birnbaum's Yiddish: A Survey and a Grammar (YSG), first published in 1979 by the University of Toronto Press. The main text is identical with that of the original, except that the more important typographical errors have been corrected. These corrections are based on an errata list plus a few additional items and changes, all compiled by the author himself, which he also noted in his own personal copy for inclusion in a future second edition. Some of these changes indicate the further development of his spelling and transcription systems. This new edition contains the following additional features:

- This preface, which includes a brief account of the author's life, and some personal reminiscences by his sons David Birnbaum (Director of the Nathan and Solomon Birnbaum Archives, Toronto) and Professor Eleazar Birnbaum (University of Toronto);

- An introduction to the work in its historical, cultural and linguistic context by Professor Kalman (Keith) Weiser, Silber Family Professor of Modern Jewish Studies, Centre for Jewish Studies, York University, Toronto;

- An historical and literary introduction by Professor Jean Baumgarten of the Centre Nationale de la Recherche Scientifique, École des Hautes Études en Sciences Sociales, and the Centre d'Études Juives, in Paris; and

- A greatly expanded bibliography. More than three decades have passed since Solomon Birnbaum's comprehensive classified bibliography appeared in the first edition of $Y S G$ (309-88).

The original bibliography is admittedly selective, reflecting Birnbaum's interests, preferences, and the sources available to him, but it remains invaluable to researchers, and its chronological organization offers a view of the evolution of the field of Yiddish Studies. The expanded bibliography in the present new 
edition draws upon the supplementary bibliographies found in the re-editions of Birnbaum's Die Jiddische Sprache as well as many newer materials. It strives to adhere as closely as possible to the norms of Birnbaum's original bibliography, including its Romanization system. Each new section of this updated bibliography follows chronologically from the relevant section of the original bibliography. The new Abbreviations section incorporates and adds to the Abbreviations section of the first edition. For this new edition, Jean Baumgarten has updated the onomastic, historical, and literary bibliographic sections ( $\mathrm{I}-2$, IO-I $5, \mathrm{I} 7-\mathrm{I} 8$ ), and Kalman Weiser has done the same for the linguistic ones and the 'Bibliographic Writings' section $(3-9,16)$.

We have also introduced a new section about Solomon Birnbaum's life and work (2I). The field of Yiddish Studies has expanded - and continues to grow - so much since the original volume of $Y S G$ was published, however, that the compilers of this extended bibliography can make no claim that it is near exhaustive. We regret that many valuable studies are not included or are not listed individually for lack of space. To remedy, if only partly, this situation, we have created a new section titled 'Yiddish Studies Collections' (20).

In the citations in the essays in this volume, the titles of Yiddish-language works, and the personal names of authors writing in Yiddish are rendered in Roman letters in two parallel forms: according to the guidelines set forth by the YIVO Institute for Jewish Research and then, after a slash, according to Solomon Birnbaum's own system, e.g. Shloyme Birnboym/Śloimy Biirnboim. In contrast, the spelling of personal names and Yiddish terms appearing in the body of the essays generally follows the conventions of contemporary scholarship. The YIVO Encyclopedia of Jews in Eastern Europe serves as our guide in most cases. Hence, for example, we use Max Weinreich in the text but Maks Vaynraykh/ Maks Vaanraax in citations. Hebrew terms and titles in the notes are Romanized according to the system employed by Solomon Birnbaum in the bibliographical section of the original edition of YSG. The same is done in the body of the essays for Hebrew items unless there exist commonly accepted spellings of them in English-language scholarship. For more on YIVO's system of Romanization for Yiddish, see Uriel Weinreich, Modern English-Yiddish Yiddish-English Dictionary (New York: YIVO, I999), xx-xi, xxiv-xxv. See also Kalman Weiser's essay in this volume for an illustrated comparison of the YIVO and Birnbaum systems for Yiddish. $^{*}$

\footnotetext{
* A Note of Appreciation

We wish to express our grateful thanks to our colleague Kalman Weiser for his special efforts in preparing this edition for publication.

Eleazar Birnbaum, David Birnbaum, and Jean Baumgarten.
} 